Correspondência 


\section{DIREITOS INTERCULTURAIS: UMA PROPOSTA PIONEIRA}

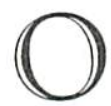

lingüista Francisco Comes de Matos (Departamento de Letras, UFPE, Recifc) é autor de um artigo $\mathrm{cm}$ favor da instituição de uma nova categoria de direitos humanos, a saber: direitos interculturais. Esse apclo foi publicado em outubro de 1997 pela FIPLV WORLID NEWVSLEETTIER, da Federação Mundial de Professores de Lúnguas Vivas, cujo XIX Congresso foi realizado na Universidade Federal de Pernambuco $\mathrm{cm}$ marrço do ano passado, sob a presidência daquele lingüista. Recentemente, o texto foi transcrito no número de fevereiro-março de Reading Today, jornal da Associação Internacional de Leitura (Newark, Delaware, ELUU).

Argumenta Comes de Matos que esses direitos interculturais não seriam derivados dos direitos culturais, mas constituiriam uma nova base sobre a qual seriam ainda mais aprofundados os direitos humanos. Assim, contribuir-se-ia para a criação de novos contextos nos quais pessoas, grupos e comunidades compreendessem e respeitassem seus sistemas de crenças, valores e atitudes, tudo isso refletido nas opçôes feitas pelos usuários das quase 5.000 línguas faladas no mundo. Para que cada professor e estudante (particularmente de línguas) possa desenvolver ao máximo sua potencialidade, os sistemas educacionais c as organizações internacionais deveriam colaborar para uma efetiva aplicação intercultural do Artigo 27(1) da Declaração Universal dos Direitos I lumanos (de 1948), segundo o qual "toda pessoa tem o direito de participar; livremente, da vida cultural da comunidade". Lembra o lingüista, Vice-Presidente da Associação Internacional para o Desenvolvimento da Comunicação Intercultural, sediada em Bruxchas, que o Artigo 28 da Declaração Universal de Direitos L Linguísticos (Barcelona, 1996), declara "Todas as comunidardes linguísticas têm direito

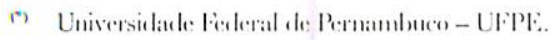




\section{Comespondência}

a uma cducação que possibilite aos scus cidadãos adquirirem um conhecimento pleno de sua herança cultural (história, geografia, litcratura c outras manifestações de sua cultura), assim como um conhecimento mais amplo possível de qualquer outra cultura que essas pessoas descjem conhecer".

O intcrculturalista pernambucano apresentou sua proposta de direitos interculturais pela primcira vez na Universidade Federal Fluminense (Nitcrói), durantc o Congresso da SIPIJE - Socicdade Intcrnacional Português língua Estrangcira, cm outubro de 1996. Eis um cxemplo de dircito intercultural de professores de línguas: "O dircito de serem preparados para interpretar percepçõcs de sua cultura nacional cxpressas por nos campos das artes, educação política, ciência, mídia, ctc. cm textos fialados ou cscritos c saber comparar tais percepções intraculturais com as de pensadores de outras culturas.

Lembra Comes de Matos que, a rigor; a dircitos interculturais corresponpodem responsabilidades c excmplifica uma destas: professores têm o dever de desafiarem scus alunos (de línguas) a identificarem c a corrigirem percepções cstcrcotipadas de aspectos de suá cultura c também da cultura a que a língua cnsinada cstcja rclacionada.

Segundo renomados intcrculturalistas, como Clairc Kramsch (autora do clássico Context and Culture in Langzaage Teaching, Oxford University Press, 1995), mesmo um aprendiz principiante de línguas estrangeiras pode scr considerado unm decisor intercultural, por isso, os programas de formação intercultural de professores precisam cstruturar-se para o preparo adequado de alunos nesta cra $\mathrm{cm}$ que os 3 princípios-chave da lícologia são compartilhados por interculturalistas: interdependência, diversidade c sustentabilidade.

Para Comes de Matos, cada professor ou aprendiz de línguas estrangeiras tem um duplo desafio: saber honrar sua identidade cultural (nacional) e saber construir uma identidade intercultural, fundada nos priircípios da comprecnsão mútua e do que cle, pionciramente, em sua Peda- 


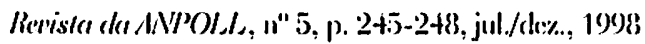

gogia da Positividade (Recife, Editora da UFPE, 1996), chama de "paz comunicativa".

\section{REPERCUSSĀO DO APELO DE GOMES DE MATOS EM FAVOR DOS DIRETTOS INIERCULTURAIS}

Mensagens recebidas, por e-mail, de especialistas de vários países:

1. Congratulations! Well said,and convincingly argued

Claire Kramsch, professora da Liniversidade da California, Berkeley c autora do clássico Context and Culture in Langucige Teaching, Oxford University Press, 1994)

2. Your concept of intercultural rights for teachers and learners look to me to be very interesting and signilicant

Robert Young, professor da Universidade de Sirlney, Austrália c autor de Intercultural Communication - Pragmalics, Cenealogy, Deconstruction M-ullilingual Malters, 1996)

3. 'Thank you for sendling the text, something which I would certainly endorse

Nancy I lornberger; professora da Universidarde da Pennsylvania, co-autora de Sociolinguistics and Language Teaching (ambrickge University Press, 1997)

4. Well done! I support you, of course

Peter Tiucigili, professor da Universidade de Latusanne, Suiça, att- 
Comrespondinciat

tor de Sociolinguistics: an Introduction to Language \&. Society (Penguin, 1983)

5. I cnthusiastically cndorse your posifion

Raymond Cohen, professor da Universidade I Icbraica de Jerusalém c autor de Negotiating Across Cultures (United States Institute of Peace Press, 1997)

6. I support you in this worthy cndcavor!

Myra Schulman, professora da Amcrican University (Washington,

D.C.) c autora de Cultures in Contrast (University of Michigan Press, 1998)

Francisco Gomes de Matos

(Departamento de Letras, UFPE, Recife) 


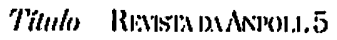

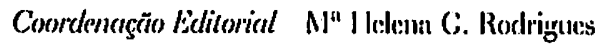

Revisoños antor(s) / Sinnone Zaccaulias

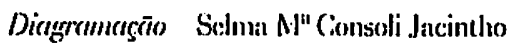

Arte-final Frbert Antĩo da Silva

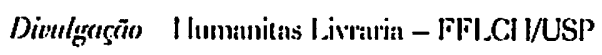

Mancher $11,5 \times 19 \mathrm{~cm}$

Fimmato $16 \times 22 \mathrm{~cm}$

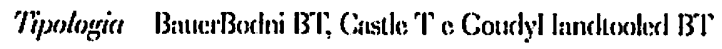

ltopel off-set $75 \mathrm{~g} / \mathrm{mol}^{2}$ (miolo)

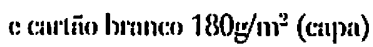

Impressäo dro copxt verde batuduira

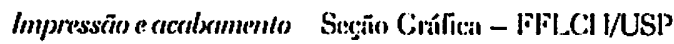

Nimere de pógrinces $2+0$

Tivrugrm 500 